\title{
Micrographia
}

\section{Structure and Composition of the Eggshell of a Passerine Bird, Setophaga ruticilla (Linnaeus, 1758)}

\author{
Yannicke Dauphin ${ }^{1 \star}$ (D), Daniel Werner ${ }^{2}$, René Corado ${ }^{3}$ and Alberto Perez-Huerta ${ }^{4}$ \\ ${ }^{1}$ ISYEB, UMR 7205 CNRS Muséum National d'Histoire Naturelle, Sorbonne-Université, EPHE, 75005 Paris, France; ${ }^{2}$ Department of Biomaterials, Max Planck Institute \\ of Colloids and Interfaces, Potsdam 14424, Germany; ${ }^{3}$ Western Foundation of Vertebrate Zoology, 439 Calle San Pablo, Camarillo, CA 93012, USA and ${ }^{4}$ Department of \\ Geological Sciences, The University of Alabama, Tuscaloosa, AL 35487, USA
}

\begin{abstract}
The mineral composition of eggshells is assumed to be a conserved phylogenetic feature. Avian eggshells are composed of calcite, whereas those of taxa within Chelonia are aragonitic. Yet, the eggshells of a passerine bird were reported to be made of aragonite. Here, we report a new study of the same bird eggshells using a combination of in situ microscopy and chemical techniques. A microstructural analysis finds a similar arrangement to other avian eggshells, despite their very thin and fragile nature. Fourier transform infrared spectrometry (FTIR) and electron backscatter diffraction (EBSD) results also confirm that the eggshells are entirely composed of calcite. Our findings demonstrate that passerine eggshells are not an exception and similar to other birds and reinforce the phylogenetic placement of this bird species.
\end{abstract}

Key words: bird eggshell, crystallography, microstructure, mineralogy

(Received 20 December 2020; revised 7 March 2021; accepted 28 March 2021)

\section{Introduction}

Biomineralized, hard eggshells are known from reptiles and birds throughout the geological record. These eggshells represent palaeoenvironmental recorders and biomarkers for stratigraphy (Pickford \& Senut, 1999; Senut, 2000) and have been used for phylogeny (Erben, 1970; Adeyeye, 2009; Pickford, 2014). Also, avian eggs are a food resource for humans and numerous animals and are used in cosmetics, dentistry, reconstructive surgery, and for vaccines, among other uses (Dupoirieux, 1999; Dupoirieux et al., 2001; Uygur et al., 2011; Kattimani et al., 2014). These studies of eggshell structure and composition were mainly based on domesticated chicken eggs.

Nathusius $(1868,1893)$ described the structure of avian eggshells of various species. From sections of the thick ostrich eggshells $(>2 \mathrm{~mm})$, the main structural layers were identified as follows: inner organic membranes, the mammillary layer, the thick spongy layer, and the thin outer prismatic layer, as well as the complex branched pores. In these large and thick eggshells, curved growth lines are well visible. The main part of the eggshell was described as composed of $\mathrm{CaCO}_{3}$, rich in $\mathrm{Mg}$ and $\mathrm{P}$, and with minor concentrations of Fe and $\mathrm{S}$, still there was no mention of the $\mathrm{CaCO}_{3}$ polymorph (calcite and/or aragonite). The main layers described by Nathusius in chicken and ostrich eggshells were largely adopted,

\footnotetext{
*Author for correspondence: Yannicke Dauphin, E-mail: yannicke.dauphin@sorbonne-universite.fr

Cite this article: Dauphin Y, Werner D, Corado R, Perez-Huerta A (2021) Structure and Composition of the Eggshell of a Passerine Bird, Setophaga ruticilla (Linnaeus, 1758). Microsc Microanal 27, 635-644. doi:10.1017/S1431927621000301
}

but there is no agreement on the descriptive terms (Romanov \& Romanov, 1949; Erben, 1970; Becking, 1975; Hincke et al., 2012). One of the first microstructural and mineralogical analyses of modern and fossil eggshells of reptiles and birds using scanning electron microscopy (SEM) and X-ray diffraction was conducted by Erben (1970). All bird and reptile eggshells are calcite, except for Testudines (turtles), called Chelonia in Erben (1970), in which aragonite was the mineral component (Fig. 1). Then, Solomon \& Baird (1976) and Baird \& Solomon (1979), using X-ray diffraction and infrared analyses, found calcite and aragonite in the inner part of the eggshell of Chelonia mydas and noticed that such bi-mineralic structure is known only in farm-reared samples.

Numerous papers are dedicated to the structure and composition of the avian eggshells (Heyn, 1963; Cain \& Heyn, 1964; Tyler, 1969a, 1969b; Becking, 1975). Tullett et al. (1976) have found a compositional difference in the outer layer of sea-bird eggshells: the organic cuticle usually described in "terrestrial" birds is replaced by a vateritic layer. Vaterite was also detected at the surface of the eggs of Crotophaga major (Portugal et al., 2018) and in nonparasitic cuckoos (Board \& Perrott, 1979). However, the main part of these eggshells was calcite. Lastly, the eggshells of an American passerine, Setophaga ruticilla (Linnaeus, 1758), were described as composed of "aragonite having a massive structure with aeration holes on the inner portion of the shell with a thin layer of microcrystalline aragonite as a coating" (Kyser et al., 2007). The description of the presence of aragonite, as the main mineral constituent, of passerine eggshells is in conflict with the use of both the structure and mineralogy for the "phylogeny" of reptile and bird eggshells (Erben, 1970; Supplementary Fig. S1).

(C) The Author(s), 2021. Published by Cambridge University Press on behalf of the Microscopy Society of America. This is an Open Access article, distributed under the terms of the Creative Commons Attribution licence (http://creativecommons.org/licenses/by/4.0/), which permits unrestricted re-use, distribution, and reproduction in any medium, provided the original work is properly cited. 


\section{ARAGONITE}

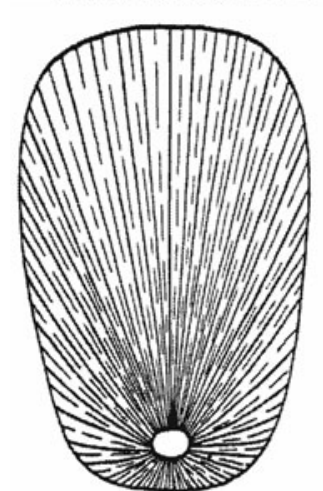

Chelonia

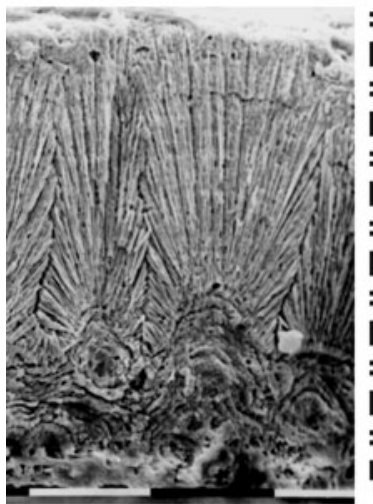

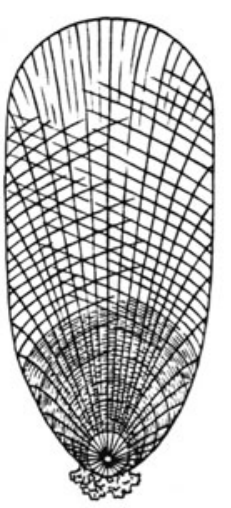

Dinosauria

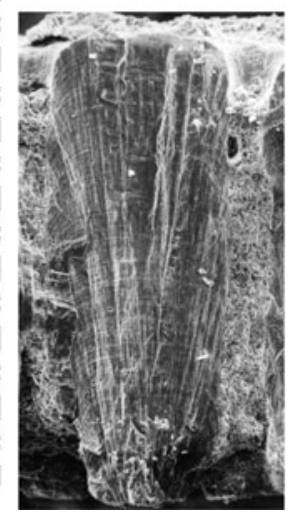

CALCITE

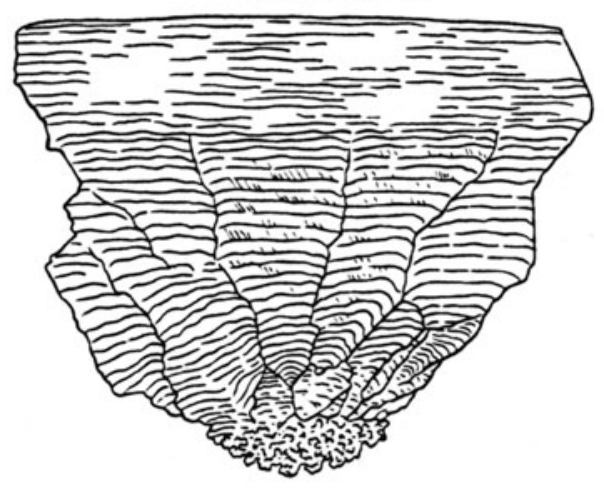

Crocodilia

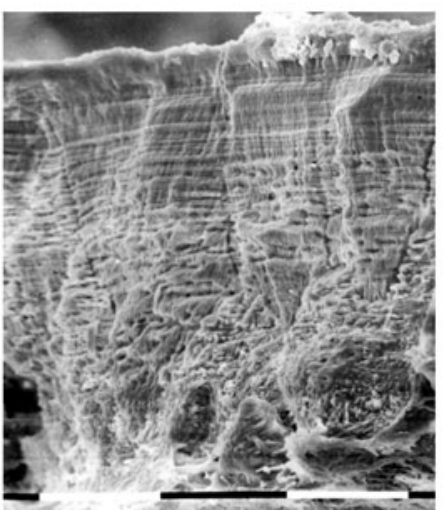

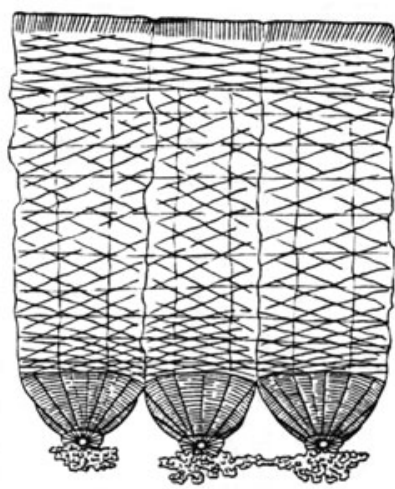

Birds

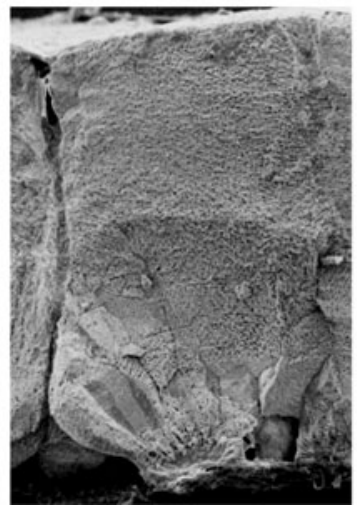

Fig. 1. Structural categories of calcified modern and fossil eggshells of reptiles and birds. Drawings from Erben (1970).

According to this concept, the first stage of differentiation was between aragonitic eggshells of Chelonia and calcitic eggshells; the second stage was between birds and "calcitic" reptiles and birds. Up to now, the oldest known bird eggshell (Lower Cretaceous of Japan) is calcite and shows a three-layered structure (Imai \& Azuma, 2014).

Setophaga (Swainson, 1827) is a genus of the Parulidae family, also called New World warblers. Twenty-five genera were traditionally assigned to this family (American Ornithologists'
Union, 1998). The monophyly of Parulidae and the phylogenetic boundaries of the family were controversial. Studies using molecular analyses have shown that some traditional families of Passerida are not monophyletic (Klicka et al., 2000). Nevertheless, mitochondrial and nuclear DNA sequences have shown that Setophaga is one of the 19 genera of the Parulidae (Lovette \& Bermingham, 2002). So, the aragonitic composition of the eggshell of Setophaga would disagree with this monophyly.
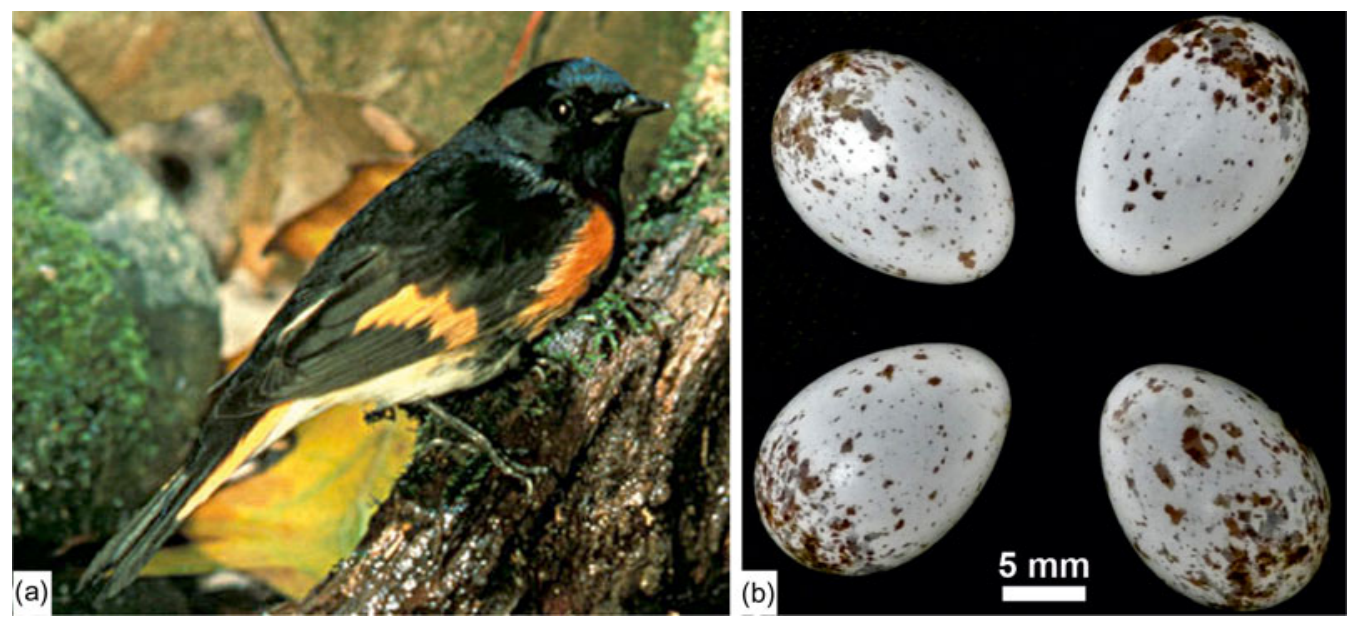

Fig. 2. Setophaga and its eggs. (a) Adult male with vivid colors (https://fr.wikipedia.org/wiki/Paruline_flamboyante\#/media/Fichier:Setophaga_ruticilla.jpg). Fish and wildlife service public domain. (b) Outer views of eggs showing the irregular brown spots, collected between 7 May and 30 June 1900 (see original labels in Supplementary Fig. S2); collections of the western foundation of vertebrate zoology. 
The aim of this study is to present a structural and compositional analysis of passerine eggshells to revisit the findings by Kyser et al. (2007). If the aragonite composition is confirmed, the eggshell phylogeny would have to be revised. However, Erben's phylogeny (1970) would prevail if these eggshells are calcitic. So, we try to answer some questions: What is the structure of the eggshell of Setophaga? What about its mineralogy? If these eggshells are aragonitic, where they are in the "phylogeny" proposed by Erben (1970) (Supplementary Fig. S1).

\section{Materials and Methods}

\section{Material (Fig. 2, Supplementary Fig. S2)}

The American redstart, Setophaga ruticilla (Linnaeus, 1758), is a small bird (11-14 cm long with the tail) that is migratory between North America and the north of South America (Supplementary Fig. S2). They are in North America for the breeding season. Sexual dimorphism is variable: the male has black and orange feathers, whereas the colors of the female are not so bright (mainly yellow, pale green, and gray). The female lays between two and five white or cream-colored eggs speckled with varying amounts of brown (Fig. 2). The average size of eggs is $17 \times$ $12 \mathrm{~mm}$.

Small fragments of eggshells obtained from the collections of the Western Foundation of Vertebrate Zoology. Fragmentary eggshell materials, collected in Newfoundland (Canada), Michigan, and Connecticut (USA), were used in this study.

\section{Scanning Electron Microscopy}

Gold-coated fractures, as well as inner and outer surfaces of the eggshells, were seen using a Zeiss EVO MA10 (Institut de Physique du Globe de Paris) and a Zeiss Gemini LEO 1550 (Max Planck Institute of Colloids and Interfaces, Potsdam) in secondary electron mode. Uncoated samples were examined using an
FEI QUANTA FEG 600 in low vacuum and both back scattered electron (BSE) and secondary electron (SE) modes (Max Planck Institute of Colloids and Interfaces, Potsdam).

BSE consists of high-energy electrons that are reflected or back-scattered out of the specimen. Since atoms with a high atomic number $Z$ are stronger scattered than light ones, they appear brighter and the resulting images contain compositional information. $\mathrm{CaCO}_{3}$ biominerals contain $\mathrm{Mg}, \mathrm{P}$, and $\mathrm{Sr}$ (Romanov \& Romanov, 1949; Jenkins, 1975; Dauphin, 1988; Dalbeck \& Cusack, 2006). These elements have higher atomic numbers than the organic components (mainly $\mathrm{H}, \mathrm{N}, \mathrm{C}$, and $\mathrm{O})$. As a result, mineral-enriched zones are brighter than those enriched in organic components.

\section{Tomography}

For the tomographic analyses, the high-resolution nanofocus computer tomography system "X-Ray Micro CT EasyTom 160" device by the company RX Solutions was used. This device includes two X-ray tubes, each with three different focal spot modes. The microtube is equipped with a tungsten filament and provides maximum power of $150 \mathrm{kV}$ and $500 \mu \mathrm{A}$. It can reach voxel sizes between 89.00 and $4.00 \mu \mathrm{m}$. The nanotube is equipped with a LaB6 filament and provides maximum power of $100 \mathrm{kV}$ and $200 \mu \mathrm{A}$. It can reach voxel sizes between 4.00 and $0.40 \mu \mathrm{m}$. In addition, a caesium iodide flat panel detector is installed.

The scan was performed by using the nanotube with $80 \mathrm{kV}$ and $80 \mu \mathrm{A}$ at the small focal spot mode. The source-detector distance was $793.31 \mathrm{~mm}$, the source-object distance was $2.50 \mathrm{~mm}$ and the resulting voxel size was $0.40 \mu \mathrm{m}$. The frame rate of the flat panel detector was 0.25 with an average of 10 frames. By collecting 1,120 images per turn, the scan time was $15 \mathrm{~h}$ after a calibration period of $2 \mathrm{~h}$. 3D reconstructions were done using FIJI and Amira software.

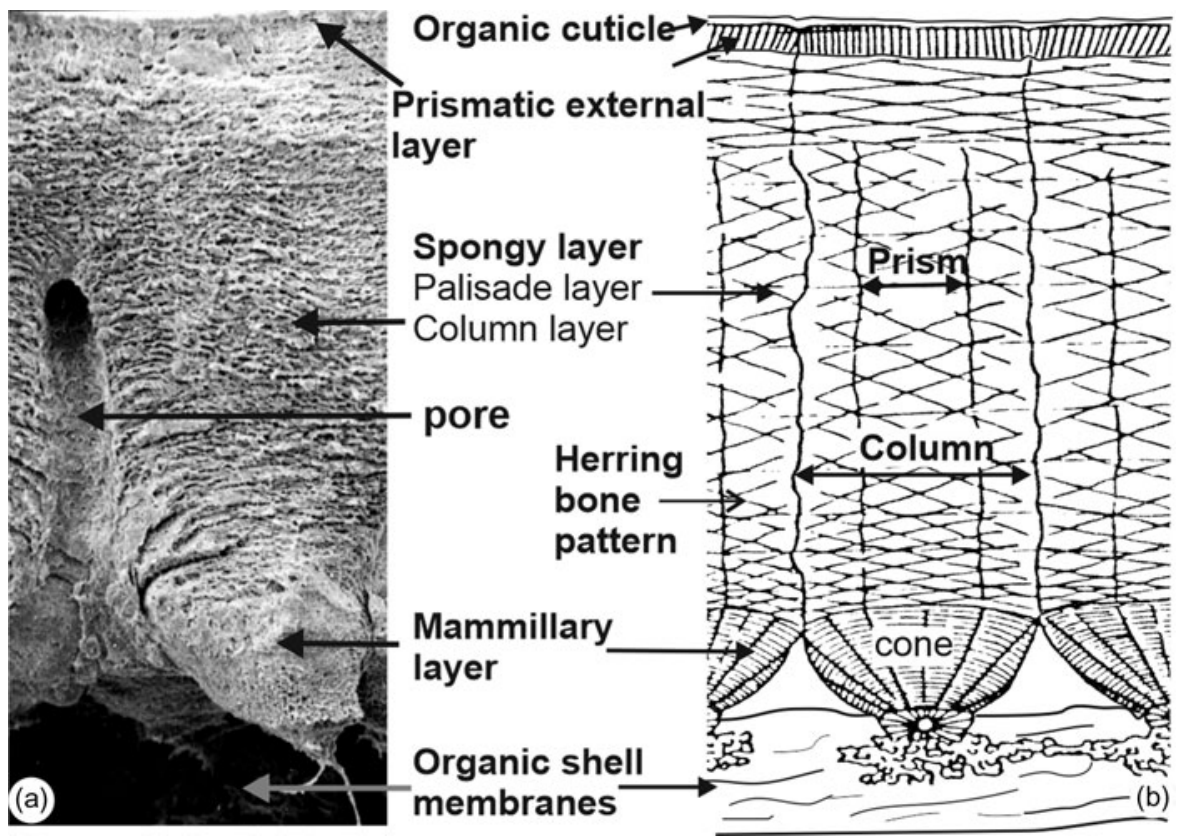

Fig. 3. Main descriptive nomenclatures used for avian eggshells. Bold words are used in this article. 


\section{Fourier Transform Infrared Spectrometry}

Fourier transform infrared spectrometry (FTIR) absorption spectrometry was carried out at the Centre de recherche sur la Conservation, CRC USR 3224 Paris) using a Continuum IR microscope coupled to a Nexus FTIR bench (Thermo Nicolet). The microscope was operated in reflection mode, where the Schwarzschild objective has a magnification of 32. Spectra were collected using a Nicolet with a resolution of $4 \mathrm{~cm}^{-1}$ and an aperture of $75 \times 75 \mu \mathrm{m}$. For each spectrum, 200 scans were accumulated in the wavenumber range $4,000-700 \mathrm{~cm}^{-1}$.

FTIR spectra of the calcite and aragonite groups are characterized by three major bands attributed to the carbonate ion $\mathrm{CO}_{3}{ }^{2-}: v 3$ at $1,429 \mathrm{~cm}^{-1}$, the $v 2$ doublet $877-848 \mathrm{~cm}^{-1}$, and $v 4$ at $713 \mathrm{~cm}^{-1}$ for calcite; $v 1$ at $1,471 \mathrm{~cm}^{-1}$, two doublets $v 2$ at $858-844 \mathrm{~cm}^{-1}$, and $v 4$ at $713-700 \mathrm{~cm}^{-1}$ for aragonite (Adler \& Kerr, 1962). Bands in these doublets are of unequal intensities. The weak carbonate $v 1$ band is at $1,012 \mathrm{~cm}^{-1}$ for calcite and at $1,083 \mathrm{~cm}^{-1}$ for aragonite. According to Ylmen \& Jäglid (2013), the $v 3$ asymmetric stretching of $\mathrm{CO}_{3}{ }^{2-}$ has a larger wavenumber range from 1,425 and $1,590 \mathrm{~cm}^{-1}$, so that an overlap with amide II bands exists.

For vaterite, $v 1$ band is at $1,085-1,090 \mathrm{~cm}^{-1}, v 2$ band is a doublet at $877-850 \mathrm{~cm}^{-1}$ (Jones \& Jackson, 1993), or $878-870 \mathrm{~cm}^{-1}$ (Andersen \& Brecevic, 1991); $v 3$ is a doublet $\left(1,491-1,420 \mathrm{~cm}^{-1}\right.$ or 1,487-1,445 $\mathrm{cm}^{-1}$ ) (Andersen \& Brecevic, 1991), or a triplet 1,408-1,432-1,489 $\mathrm{cm}^{-1}$ (Jones \& Jackson, 1993); $v 4$ doublet varies from 748 to $668 \mathrm{~cm}^{-1}$ (Jones \& Jackson, 1993) and 750 to $738 \mathrm{~cm}^{-1}$ (Andersen \& Brecevic, 1991).

\section{Raman Spectroscopy}

Raman spectra were collected using a InVia Raman microspectrometer (Renishaw) controlled by the WiRE software

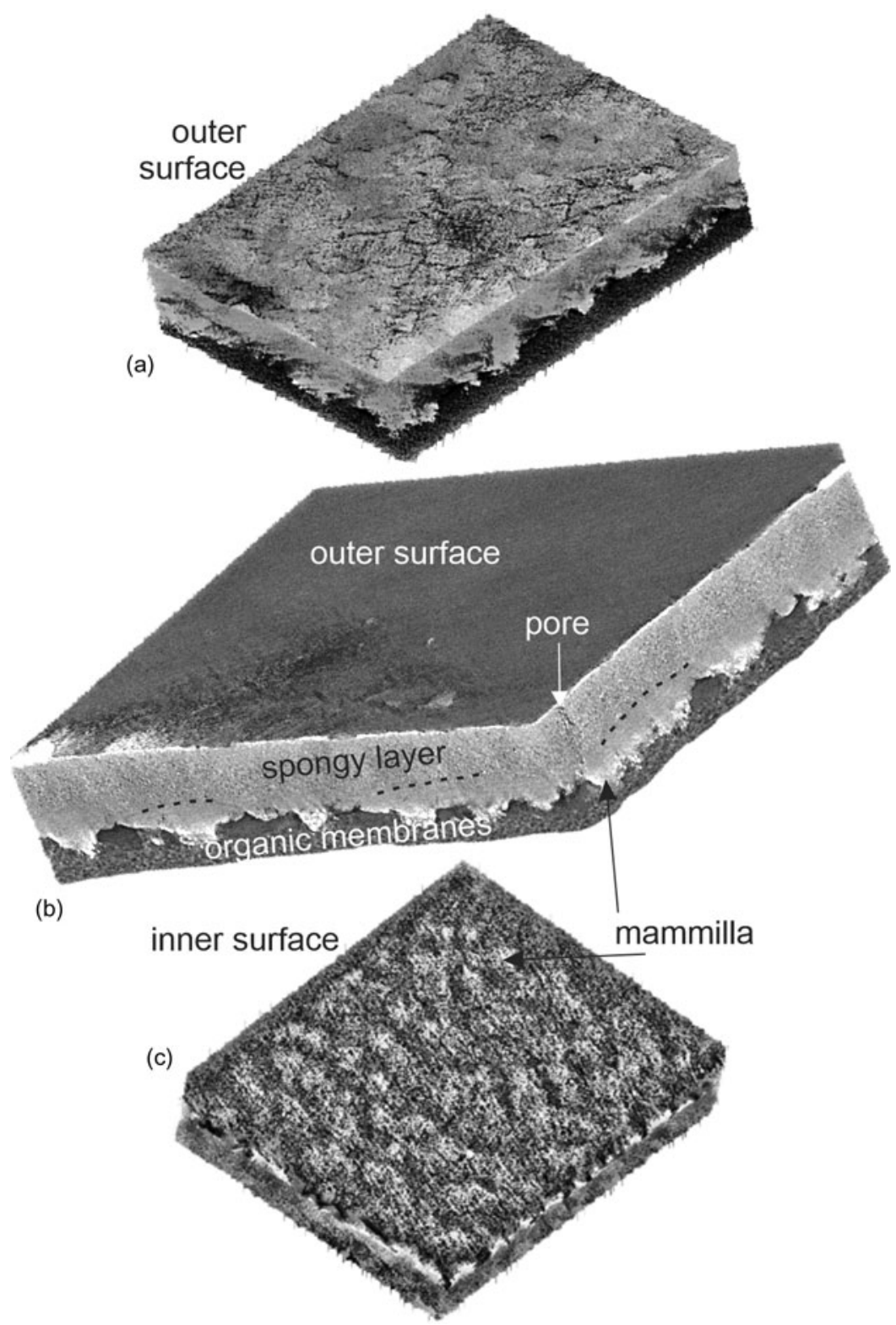

Fig. 4. Three CT dimensional reconstructions showing the main structural features of the eggshell of Setophaga. (a) Outer surface with an irregular polygonal pattern. (b) Oblique view showing the main layers of the eggshell. (c) Inner surface showing the fibrous organic membranes and the calcified mammillae. 
(CRC, Paris). Data were collected with a $785 \mathrm{~nm}$ laser and a 1,200 lines $/ \mathrm{mm}$ grating, within the spectral window $100-1,600 \mathrm{~cm}^{-1}$, using $1 \%$ of the laser power. Another series of spectra was acquired using a $532 \mathrm{~nm}$ laser and a 1,800 lines/mm grating from 100 to $1,600 \mathrm{~cm}^{-1}$ with $0.1 \%$ of the laser power. For each analyzed spot, data were scanned for the acquisition of up to 10 spectra and $10 \mathrm{~s}$ laser exposure time. Spot positioning was made using a $50 \times$ objective lens, giving an analytical spot size of approximately $2 \mu \mathrm{m}$ in diameter. Spectra were then normalized and averaged. Spectral peak positions were calibrated with a silicon standard. Spectra baseline was corrected using the Crystal Sleuth routine and the wavenumbers were identified by Spectragryph (F. Menges, optical spectroscopy software, http:// www.effeOctober 3, 2019mm2.de/spectragryph/).

Calcite peaks are located at 156 and $282 \mathrm{~cm}^{-1}$ (lattice mode), $v 4$ at $711 \mathrm{~cm}^{-1}, v 1$ at $1,087 \mathrm{~cm}^{-1}$, and $v 3$ at $1,435 \mathrm{~cm}^{-1}$. Aragonitic peaks are at 152,182, 209, 217, and $275 \mathrm{~cm}^{-1}$ (lattice mode), a $v 4$ doublet at $702-706 \mathrm{~cm}^{-1}, v 1$ at $1,084 \mathrm{~cm}^{-1}$, and $v 3$ at $1,462 \mathrm{~cm}^{-1}$ (Urmos et al., 1991; Nehrke et al., 2012).

Five main regions are experimentally identified in vaterite: lattice mode $(L)$ from 0 to $340 \mathrm{~cm}^{-1}, v 4$ at $666-685 \mathrm{~cm}^{-1}$ and $738-$ $783 \mathrm{~cm}^{-1}, v 2$ at $873-881 \mathrm{~cm}^{-1}, v 1$ at $1,071-1,091 \mathrm{~cm}^{-1}$, and $v 3$ at $1,421-1,555 \mathrm{~cm}^{-1}$ (De La Pierre et al., 2014).

\section{Electron Backscatter Diffraction}

Three small eggshell fragments $\left(\sim 0.5 \mathrm{~cm}^{2}\right)$ were embedded in epoxy resin and subsequently ground and polished using the sequence described in Perez-Huerta \& Cusack (2009). Once the sample was polished, the surface was coated with $2.5 \mathrm{~nm}$ of carbon. The electron backscatter diffraction (EBSD) analysis was carried out with an Oxford Nordlys camera mounted on a Field Emission Scanning Electron Microscope (FESEM) JEOL 7000 located in the Alabama Analytical Research Center (AARC) of the University of Alabama. EBSD data were collected with Oxford Aztec 2.0 software at high vacuum, $20 \mathrm{kV}$, a large probe current of 16A, working distance of $11 \mathrm{~mm}$, and a resolution of $1 \mu \mathrm{m}$ step size. Finally, data were analyzed using the OIM 5.3 software from EDAX-TSL. In this study, EBSD data are represented by diffraction intensity, mineral phase, and crystallographic maps and pole figures in reference to the $\{0001\}$ plane of calcite (see also Perez-Huerta \& Dauphin, 2016).

\section{Results and Discussion}

The most common nomenclatures used to describe the structure of calcified eggshells are shown in Figure 3, and bold words are the terms used in this manuscript. Overall, despite its thinness, the usual layered structure of avian eggshells exists in the eggshell of Setophaga. It must be noted that in such small dried and old collected fragments, the outer organic cuticle is not always preserved.

\section{Microstructural Layers (Figs. 4-7)}

Three computer tomography (CT) dimensional reconstructions show the main layers of the eggshell (Fig. 4). The irregular outer surface shows a polygonal pattern (Fig. 4a). The palisade and mammillary layers are distinct, but the outer prismatic layer, present in other avian eggshells, is not visible (Fig. 4b). The examination of the inner surface shows the presence of the fibrous organic membrane and the protuberant mammillae (Fig. 4c).

Images extracted from tomography data show the irregular polygons and thin cracks of the outer surface of the sample (Fig. 5a). Similar features are also visible in SEM images (Figs.
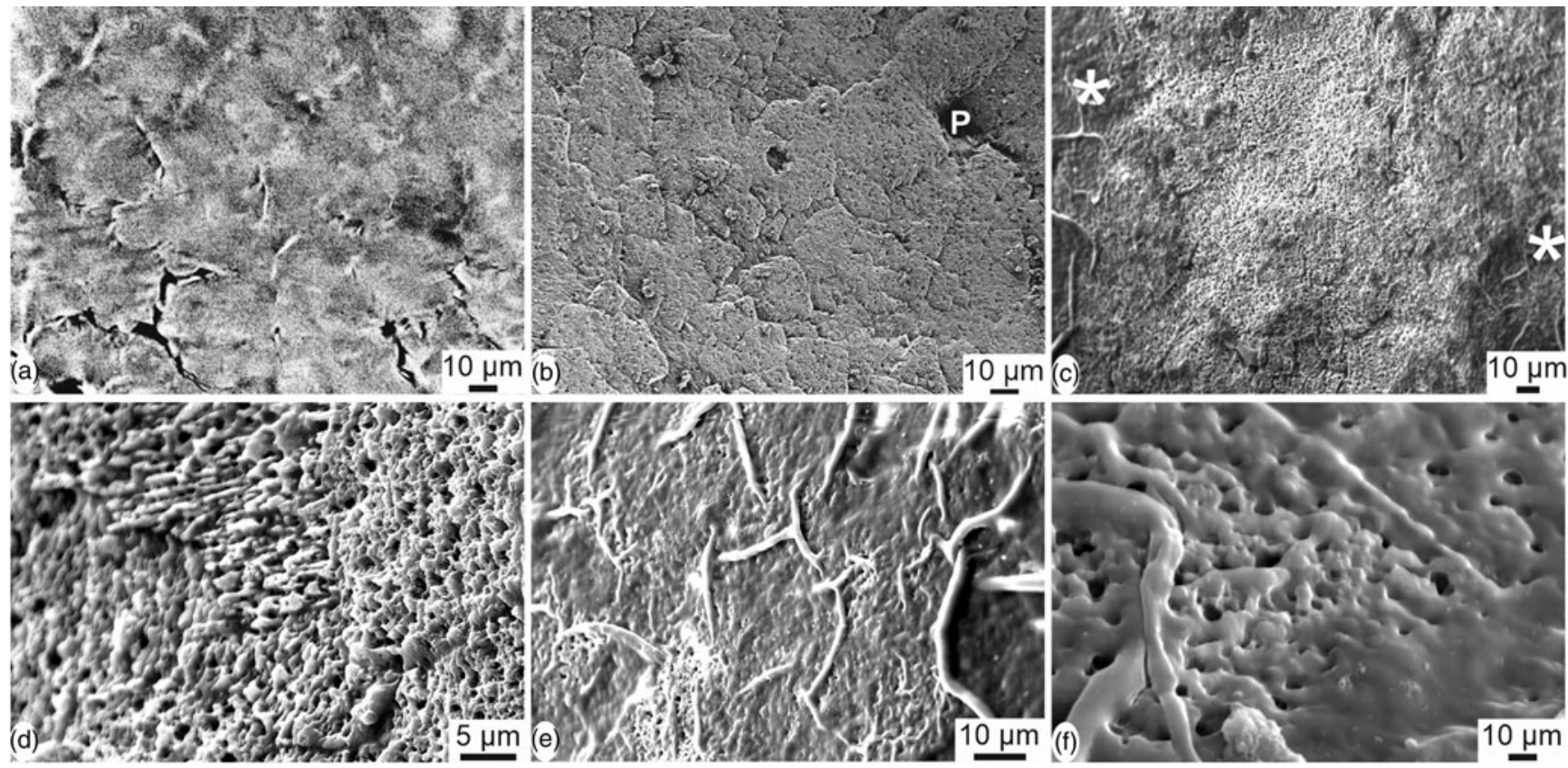

Fig. 5. Outer surface of the eggshell of Setophaga. (a) CT scan reconstruction showing the irregular polygonal pattern of the outer surface; the outer thin organic cuticle is destroyed. (b) SEM image showing the polygonal pattern and a pore (P), the outer pellicle being destroyed. (c) Some polygons and the thin organic cuticle are visible on the left and right sides of the image $\left(^{*}\right)$; the organic cuticle is destroyed in the main central part. (d) Detail showing the small acicular crystallites with various orientations, the outer pellicle being destroyed. (e) Polygons are surrounded by an organic bulge when the outer organic cuticle is preserved. (f) Detail of the spongy outer surface still coated with the organic cuticle. 
$5 b-5 d)$, with the outer organic cuticle being partially destroyed. Pores seem to be oval or round with a single opening (Figs. 5b, $5 \mathrm{c})$. Within the polygons, the orientation of elongated crystallites varies (Fig. 5d). When the organic cuticle is still preserved, the irregular polygonal arrangement is more apparent (Fig. 5e) and the numerous small holes are visible (Fig. 5f).

Sections across the eggshell thickness show all the layers known in avian eggshells (Fig. 6): the inner organic membranes (OMs), the spherolites and the mammillary layer (ML), the spongy layer (SL) and pores. Depending on the preservation of the sample, the outer prismatic layer and the organic cuticle are also visible. The thickness of the eggshell is about $40-50 \mu \mathrm{m}$. Abundant small rounded vesicles exist in the spongy layer (Figs. $6 a-6 c, 6 e, 6 f)$. Spherolites and mammillae are not contiguous as shown when the inner membranes are partially destroyed (Figs.
$6 a-6 c)$. The blocky structure is mainly visible in the mammillary layer and in the outer part of the spongy layer (Figs. 6c, 6i-6j). Growth lines and the herringbone pattern usually seen in avian eggshells are not revealed in these sections, but it must be said that these microstructural features are most often described on polished samples. Locally, thin platelets more or less parallel to the outer surface are visible (Fig. 6d). These platelets are an assemblage of elongated acicular crystallites, which are composed of rounded granules (Fig. 6e). Vesicles do not show a preferential orientation (Figs. 6e, 6f). The structure of the prismatic external layer is variable, as shown in Figures $6 \mathrm{~g}-6 \mathrm{i}$ : crystallites are sometimes perpendicular to the outer surface of the shell (Fig. 6g). The outer organic cuticle is locally preserved on the outer surface (Fig. 6h). Prisms of the external layer are perpendicular to the surface, as shown in Figure 6g, but they are more compact (Fig. 6i).
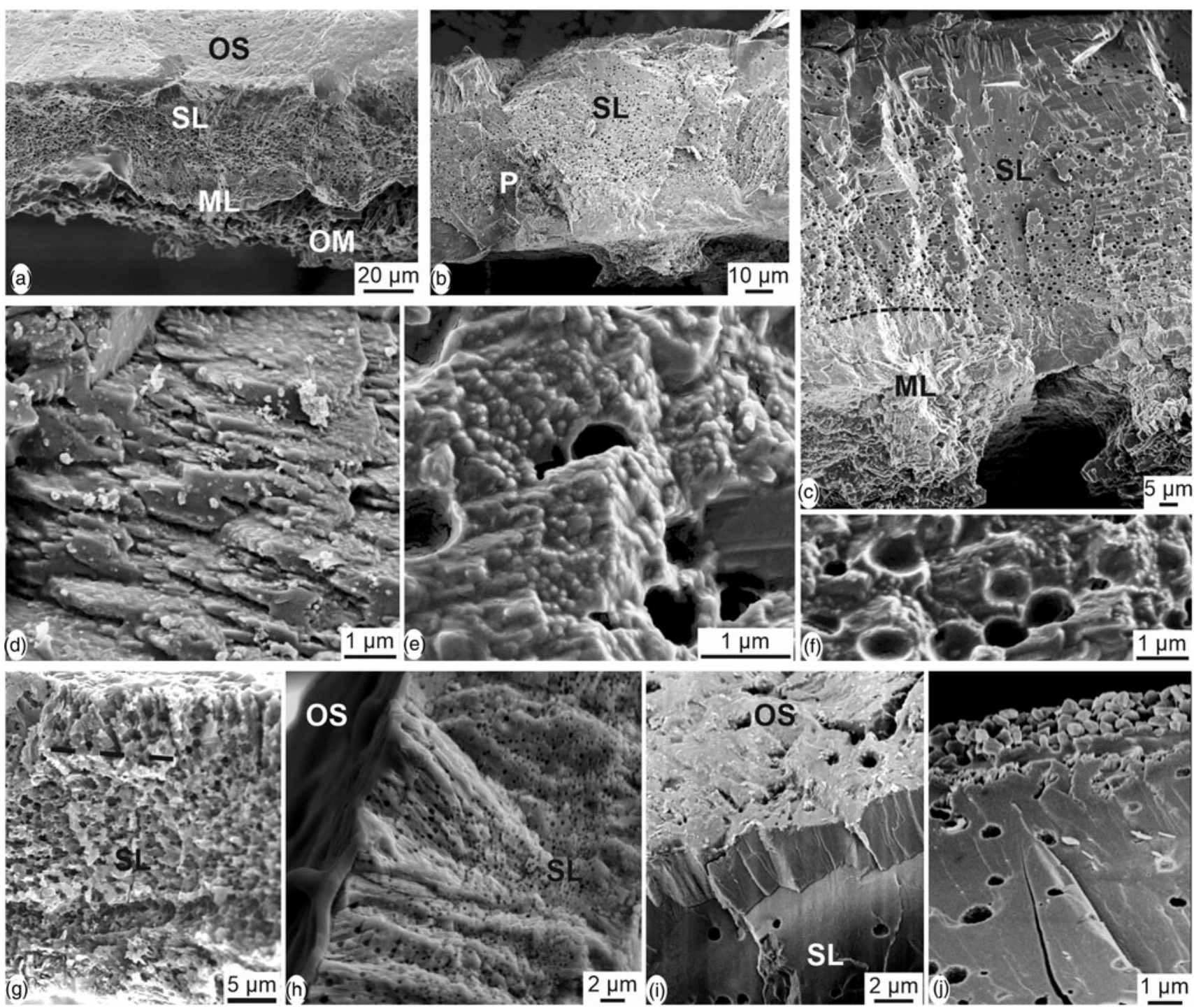

Fig. 6. Vertical sections through the thickness of the eggshell of Setophaga. (a) Fracture showing the large and flat shape of the structural units from the mammilla (ML) toward the outer surface. The outer surface is coated with the very thin organic cuticle as shown by its smooth aspect (OS). Inner organic membranes are locally preserved (OM). (b) Fracture showing the spongy structure of the main layer (SL); the mammillary layer seems more compact and the inner membranes are absent. P, pore. (c) Vertical fracture showing all the mineral layers of the eggshell. Round vesicles are not visible in the mammillary layer (ML). (d) Thin platelets parallel to the outer surface of the eggshell. (e) Elongated crystallites composed of rounded granules. (f) Round vesicles in the spongy layer. (g) Boundary between the spongy layer (SL) and the thin outer prismatic layer is not sharp. (h) The outer organic cuticle is preserved on the outer surface (OS); (i) diverse aspects of the outer part of the spongy layer and the external prismatic layer, depending on the preservation of the dried eggshells. 
In some places, granular microcrystals with no visible preferred orientation also exist (Fig. 6j). Vertical sections show that the inner mammillary layer and the spongy layer are always visible, whereas the thin outer prismatic layer and the organic cuticle are variable.

Oblique CT scan reconstruction show the layered arrangement of the inner part of the eggshell and emphasize the difference between the organic and mineral components (Fig. 7a). The inner fibrillar organic membranes are dark, whereas the spherolitic structures of isolated calcified mammillae are white. Depending on the preservation, the fibrillar membranes attached at the basal part of the mammillae are more or less abundant (Figs. 7b, 7c). The size and shape of the spherolites in the mammillary layer are variable. The inner surface and vertical view show the fibers of the inner organic membranes anchored in the calcareous cone structures (Figs. $7 \mathrm{~d}, 7 \mathrm{e}$ ). The arrangement of the smooth organic fibers is not compact (Fig. 7f).

\section{Mineralogy}

Mineralogy has been analyzed using FTIR and Raman spectrometry. FTIR is sensitive to $\mathrm{H}_{2} \mathrm{O}$ and $\mathrm{CO}_{2}$ present in the atmosphere and sample, whereas Raman is sensitive to fluorescent compounds.

For FTIR characterization, the strongest band in calcite and aragonite is $v 3$, between 1,400 and $1,500 \mathrm{~cm}^{-1}$ (Supplementary Fig. S3a). Bird eggshells are composed of mineral and organic matrix as shown by the spectra acquired on the outer and inner surfaces of Setophaga eggshells. The difference between the spectra of the outer surface can be assigned to some difference in color, but the strong difference between the outer and inner surfaces is due to the remains of the inner organic membranes (Supplementary Fig. S3b). Moreover, there is a large overlap in the $v 3$ region $\left(1,400-1,500 \mathrm{~cm}^{-1}\right)$ between bands assigned to calcite, aragonite, and some organic components (Supplementary Fig. S2b). So, only $v 2$ and $v 4$ bands are used to discriminate between the minerals (Fig. 8).

Nonbiogenic calcite and aragonite spectra clearly show the difference in the wavenumbers of $v 2$ band $\left(872 \mathrm{~cm}^{-1}\right.$ for aragonite and $882 \mathrm{~cm}^{-1}$ for calcite) (Fig. 8a). In aragonite, $v 4$ is a doublet (Fig. 8a). Spectra acquired on the outer surface of the eggshells of domesticated chicken and Setophaga show that the $v 2$ band is at $882 \mathrm{~cm}^{-1}$, indicative of calcite (Fig. 8b). In all samples, $v 4$ is a single band at $712 \mathrm{~cm}^{-1}$, as for calcite. Bands usually assigned to vaterite are absent.

Nonbiogenic calcite and aragonite Raman spectra are displayed in Figure 9a. $v 1 \quad\left(1,080-1,090 \mathrm{~cm}^{-1}\right)$ and $v 4$ (700$720 \mathrm{~cm}^{-1}$ ) peaks are "internal modes" due to vibrations between $\mathrm{C}$ and $\mathrm{O}$ of $\mathrm{CaCO}_{3}$. "Lattice" or "external" modes in the region $100-400 \mathrm{~cm}^{-1}$ are absent in ACC and differ in crystalline $\mathrm{CaCO}_{3}$ (Fig. 9a; Gierlinger et al., 2013; Ramesh et al., 2018). Both samples show the peaks characteristic for these polymorphs, but aragonite also comprises some peaks probably due to the presence of organic components. Peaks at $1,210 \mathrm{~cm}^{-1}$ and $1,245 \mathrm{~cm}^{-1}$ are known in mollusk shells (Thompson et al., 2014), and peaks at $1,334-1,336 \mathrm{~cm}^{-1}$ are described in the nacreous layers of several bivalve species (Zhang et al., 2001). The presence of organic components is not rare in nonbiogenic aragonite (Dauphin \& Perrin, 1992).

Raman spectra of the outer and inner surfaces of the eggshell are similar and indicative of calcite. The strong broad peaks from 100 to $300 \mathrm{~cm}^{-1}$ are the characteristics of amorphous or poorly
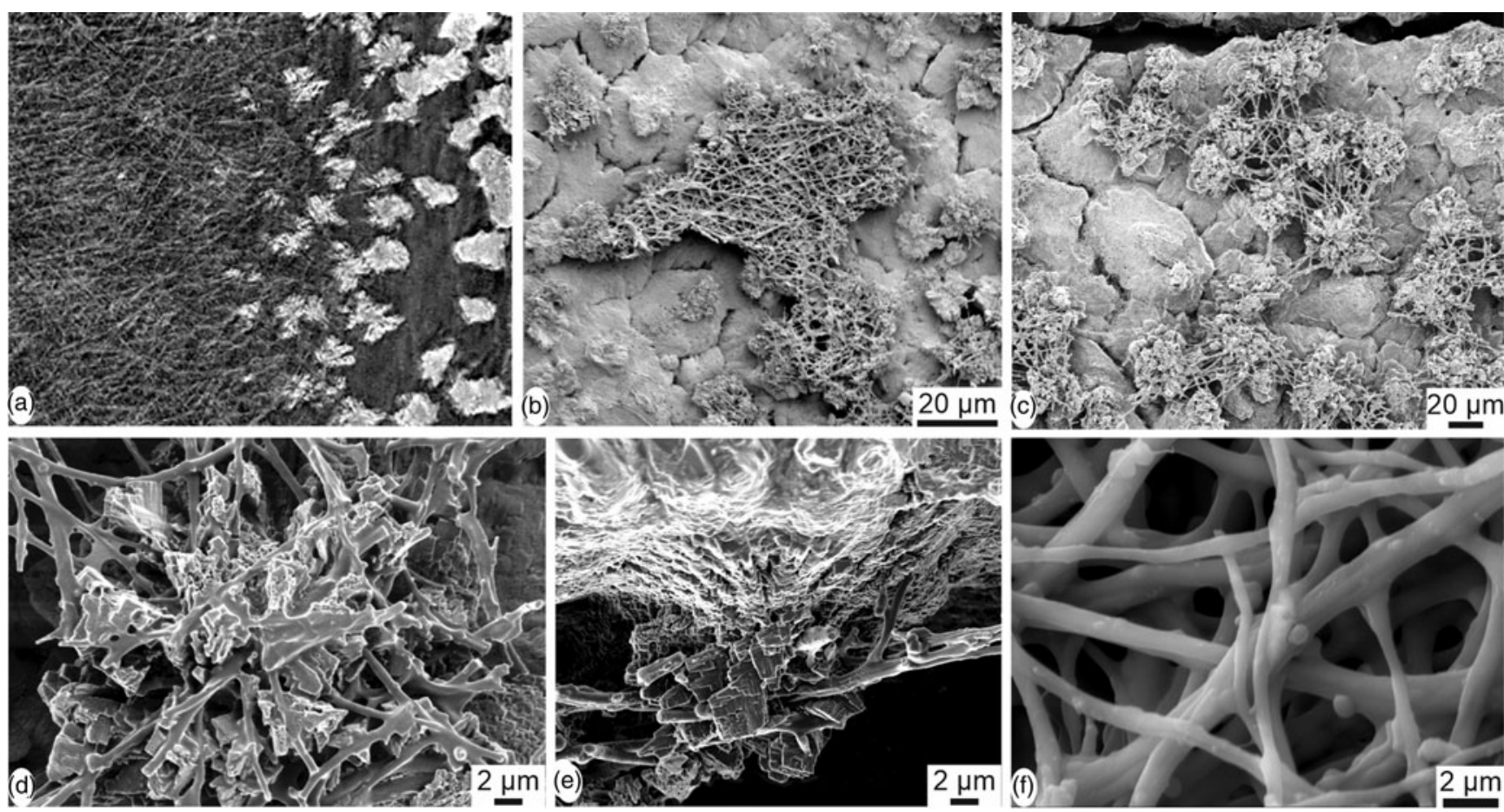

Fig. 7. Inner surface of the eggshell of Setophaga. (a) CT scan oblique reconstructed slice showing the fibrous organic membrane (dark) and the calcified dispersed mammilla (white). (b) SEM image showing a piece of the fibrous membrane. (c) Partially destroyed organic membrane showing the first calcified layers of the mammillary layer; the shape and size of the mammillary units are variable. (d) Remains of the fibrous membrane anchored in the mammilla. (e) Detailed view of the insertion of the organic fibres in the calcareous mammilla. (f) Nodes and smooth aspect of the organic fibres. 

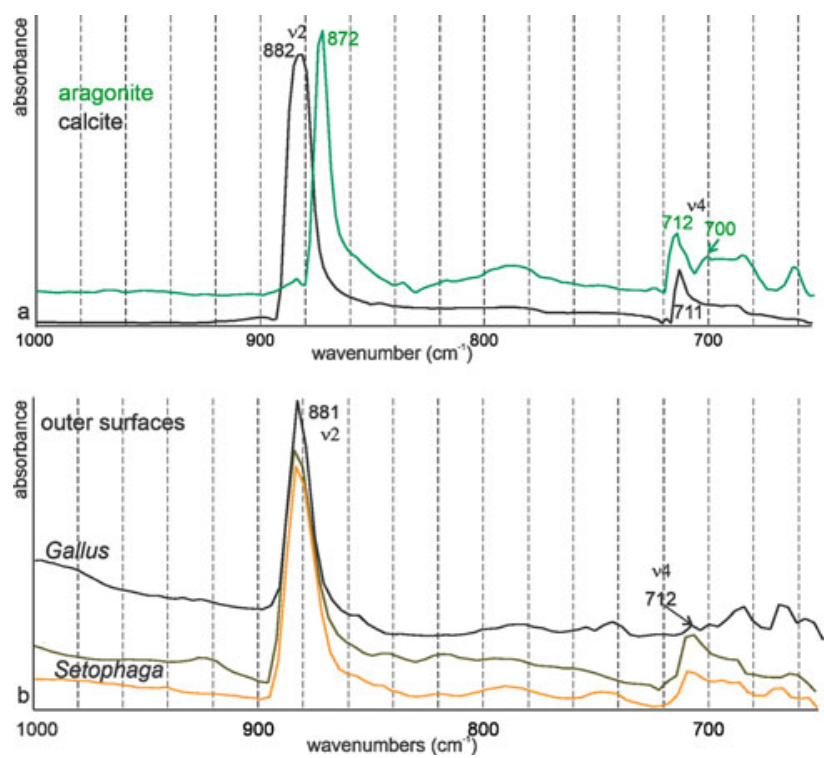

Fig. 8. FTIR spectra of nonbiogenic calcite and aragonite (a) and of the surfaces of Gallus and Setophaga (b). Both eggshells are calcite.
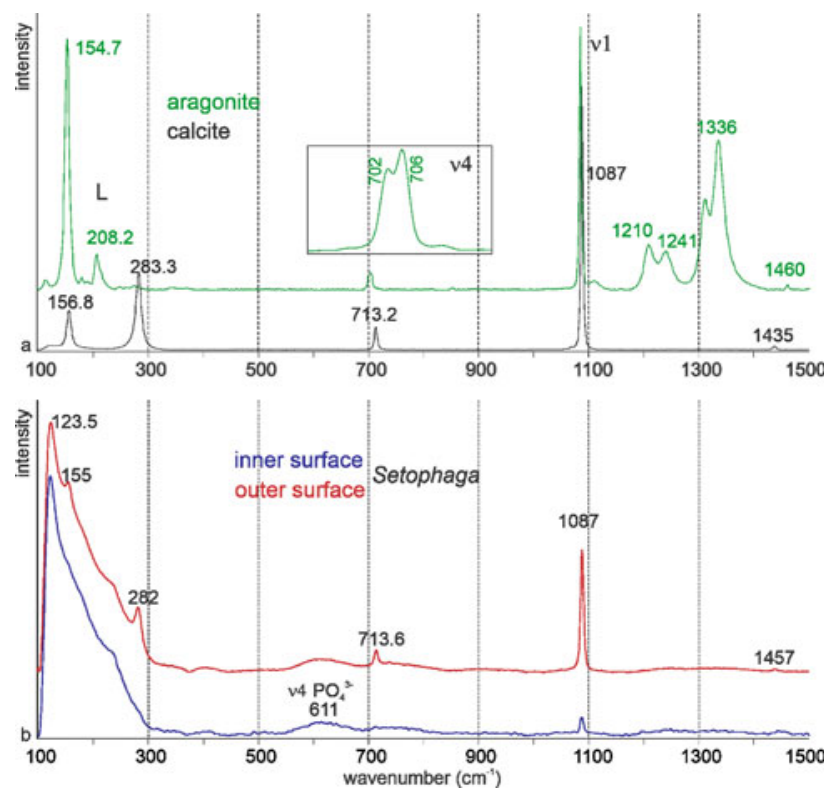

Fig. 9. Raman spectra of nonbiogenic calcite and aragonite (a) and of the surfaces of Setophaga (b), indicative of calcite.

crystalline calcium carbonate (Neues et al., 2011). A bump near $610 \mathrm{~cm}^{-1}$ visible in both surfaces can be assigned to phosphate and/or proteins. Some peaks are weaker or are visible as bumps in the spectrum of the inner surface $\left(282\right.$ and $\left.713 \mathrm{~cm}^{-1}\right)$, due to the presence of remains of the inner organic membranes. The broad peak from 60 to $290 \mathrm{~cm}^{-1}$ is the characteristic of unstable amorphous calcium carbonate.

\section{Crystallography}

The EBSD analyses provide information about mineralogy and crystallographic orientations in relation to the microstructure. These analyses were conducted across the eggshell thickness,
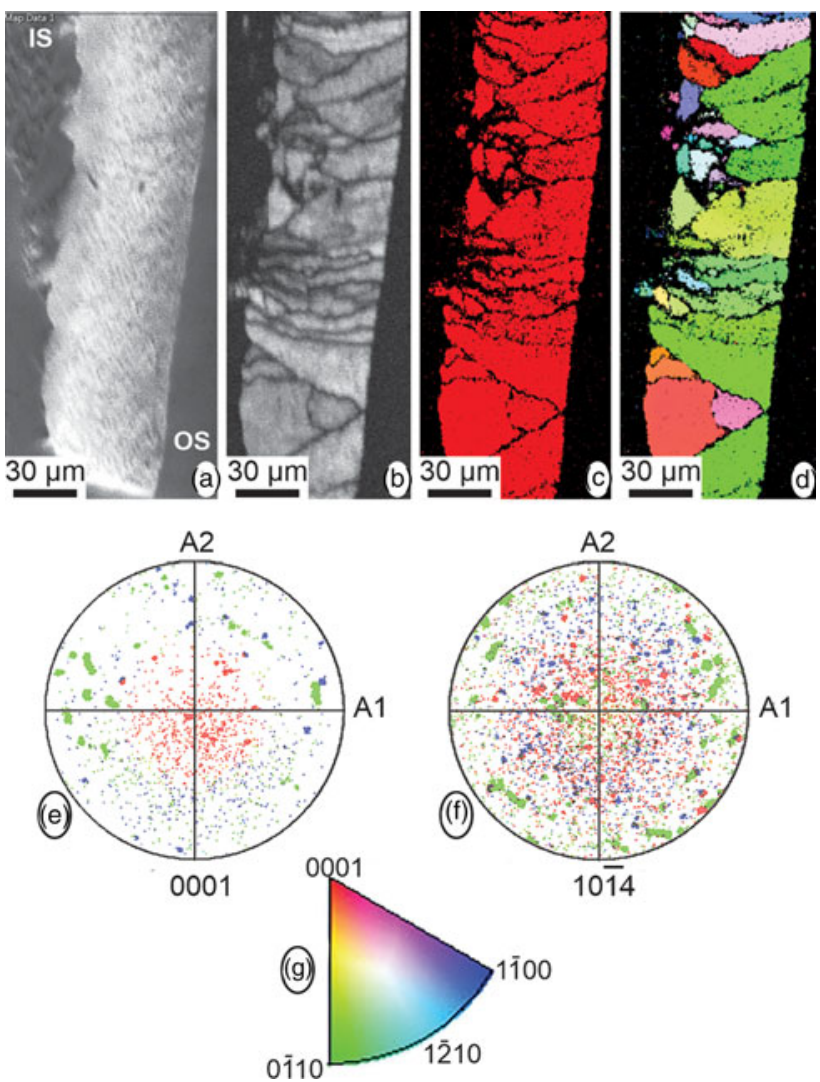

Fig. 10. EBSD data. (a-d) Maps showing, from left to right, the SEM image across the eggshell thickness (IS, internal shell; OS, outer shell), the diffraction intensity map, the phase map, with only one color (red) corresponding to calcite, and the crystallographic map. (e,f) Pole figures, in reference to the $\{001\}$ and $\{104\}$ planes of calcite, for the crystallographic map. (g) Color-key legend for the interpretation of the orientation of crystallographic planes in crystallographic map and pole figures.

although most of the inner organic membranes and the mammillary layer were lost during sample preparation due to the shell thickness and fragility. Most of the EBSD data corresponds to the spongy layer, with some information from the very thin prismatic external layer that shows crystallographic continuity (Fig. 10). Although calcite, aragonite, and vaterite phases were added to the analysis, only the presence of calcite was detected. The spongy layer has high crystallinity with a prismatic-blocky structure, and weak overall calcite $c$-axis oriented perpendicular to the outer surface (Fig. 10).

\section{Conclusion}

Our study shows that the porous microstructure of the eggshell of Setophaga is similar to that of other birds with the following arrangement: inner organic fibrous membranes, the mammillary layer with spherolitic arrangement, the palisade layer with numerous small vesicles, a thin outer prismatic layer, and the outer organic cuticle. FTIR and Raman spectrometry data show that the eggshell is calcite. Neither aragonite nor vaterite has been detected. From Raman spectra, amorphous calcium carbonate seems present, but ACC is not visible in the FTIR spectra. EBSD results confirm these results. The overall crystallographic arrangement, with less order and control of the calcite $a-, b$-, and $c$-axes, is similar to that previously described for quail and pheasant eggshells (Dalbeck \& Cusack, 2006). 
Variability of the mineralogy of carbonate skeletons is rare within a taxon, as, for example, all echinoderm skeletal components are calcitic. Nevertheless, some exceptions are well-known. Among them, a classical example is the aragonitic skeleton of an Heliopora octocoral (also called blue coral), whereas the skeletons of other species within the Subclass Alcyonaria are calcitic. This supports the idea that the mineralogy in biomineralized structures is a conserved phylogenetic feature. Thus, the same mineralogy and overall microstructural arrangement are expected for avian eggshells. Kyser et al. (2007) described the finding aragonite in Setophaga eggshells contradicted our knowledge of biomineralization processes in the context of phylogeny. However, we could not find the presence of aragonite in our study and the mineralogy (calcite) and structural arrangement of Setophaga eggshells are similar to those of other birds. These results support the phylogeny proposed by Erben (1970), and the fact that Setophaga is a Parulidae (Lovette \& Bermingham, 2002).

Supplementary material. To view supplementary material for this article, please visit https://doi.org/10.1017/S1431927621000301.

Acknowledgments. The authors are grateful to two anonymous reviewers and the editor for their detailed and insightful comments that have significantly improved the manuscript. This study utilized resources owned and maintained by the Alabama Analytical Research Center (AARC), which is supported by The University of Alabama (USA). SEM and CT scan analyses were done using facilities of the Max Planck Institute of Colloids and Interfaces (Potsdam, Germany). Infrared and Raman data were obtained using resources of the Museum national d'histoire naturelle (CRC USR 3224, Paris, France).

Financial Support. This research did not receive any specific grant from funding agencies in the public, commercial, or not-for-profit sectors.

Conflict of Interest. The authors declare no conflict of interest.

\section{References}

Adeyeye E (2009). Comparative study on the characteristics of egg shells of some bird species. Bull Chem Soc Ethiopia 23(2), 159-166.

Adler HH \& Kerr PF (1962). Infrared study of aragonite and calcite. Am Mineral 47, 700-717.

American Ornithologists' Union (1998). Check-List of North American Birds, 7th ed. Washington, DC: American Ornithologists' Union.

Andersen FA \& Brecevic L (1991). Infrared spectra of amorphous and crystalline calcium carbonate. Acta Chem Scand 45, 1018-1024.

Baird T \& Solomon SE (1979). Calcite and aragonite in the egg shell of Chelonia mydas L. J Exp Mar Biol Ecol 36, 295-301.

Becking JH (1975). The ultrastructure of the avian eggshell. Ibis 117(2), 143151.

Board RG \& Perrott HR (1979). Vaterite, a constituent of the eggshells of the nonparasitic cuckoos, Guira guira and Crotophagi ani. Calcif Tissue Int 29, 63-69.

Cain C \& Heyn A (1964). X-ray diffraction studies of the crystalline structure of the avian egg shell. Biophys J 4, 23-39.

Dalbeck P \& Cusack M (2006). Crystallography (electron backscatter diffraction) and chemistry (electron probe microanalysis) of the avian eggshell. Crystal Growth Design 6(11), 2558-2562.

Dauphin Y (1988). Particularités des teneurs en Mg et Sr de l'aragonite et de la calcite des coquilles d'oeufs de reptiles et d'Oiseaux. C R Acad Sci Paris 306 (sér II), 835-840.

Dauphin Y \& Perrin C (1992). Mise en évidence de la présence de matière organique dans un ciment d'aragonite botryoidale par spectrométrie infrarouge à transformée de Fourier (FTIR). J Geol Paläont Abh 186, 301-319.

De La Pierre M, Demichelis R, Wehrmeister U, Jacob DE, Raiteri P, Gale JD \& Orlando R (2014). Probing the multiple structures of vaterite through combined computational and experimental Raman spectroscopy. J Phys Chem 118, 27493-27501.

Dupoirieux L (1999). Ostrich eggshell as a bone substitute: A preliminary report of its biological behaviour in animals - A possibility in facial reconstructive surgery. Br J Oral Maxil Surg 37, 467-471.

Dupoirieux L, Pourquier D, Neves M \& Téot L (2001). Resorption kinetics of eggshell: An in vivo study. J Craniofac Surg 12(1), 53-58.

Erben HK (1970). Ultrastrukturen und mineralisation rezenter und fossiler eischalen bei vögeln und reptilien. Biomineralization 1, 1-66.

Gierlinger N, Reisecker C, Hild S \& Gamsjaeger S (2013). Raman microscopy: Insights into the chemistry and structure of biological materials. In Materials Design Inspired by Nature: Function Through Inner Architecture, Fratzl P, Dunlop JWC \& Weinkamer R (Eds.), pp. 151179. Cambridge, UK: RSC Publishing.

Heyn ANJ (1963). The crystalline structure of calcium carbonate in the avian egg shell - An electron microscope study. J Ultrastruct Res 8, 176-188.

Hincke MT, Nys Y, Gautron J, Mann K, Rodriguez-Navarro AB \& McKee MD (2012). The eggshell: Structure, composition and mineralization. Front Biosci 17, 1266-1280.

Imai T \& Azuma Y (2014). The oldest known avian eggshell, Plagioolithus fukuiensis, from the Lower Cretaceous (upper Barremian) Kitadani Formation, Fukui, Japan. Hist Biol 27, 1090-1097.

Jenkins NK (1975). Chemical composition of the eggs of the crocodile (Crocodylus novaeguinaea). Comp Biochem Physiol 51 A, 891-895.

Jones GC \& Jackson B (1993). Infrared Transmission Spectra of Carbonate Minerals. London: Chapman and Hall.

Kattimani VS, Chakravarthi PS, Kanumuru NR, Subbarao VV, Sidharthan A, Sampath Kumar TS \& Prasad LK (2014). Eggshell derived hydroxyapatite as bone graft substitute in the healing of maxillary cystic bone defects: A preliminary report. J Int Oral Health 6(3), 15-19.

Klicka J, Johnson KP \& Lanyon SM (2000). New world nine-primaried oscine relationships: Constructing a mitochondrial DNA framework. Auk 117, 321-336.

Kyser K, Radcliffe L \& Langin K (2007). Mineralogy and chemistry of passerine egg shells as a reflection of geosphere-biosphere interactions and changing ecology. Frontiers in Mineral Sciences, 26-28 June 2007, Cambridge, UK. BO8 abstract.

Lovette IJ \& Bermingham E (2002). What is a wood-warbler? Molecular characterization of a monophyletic Parulidae. Auk 119, 695-714.

Nathusius von Königsborn W (1868). Über die hüllen, welche den dotter des vogeleies umgeben. Z Wissensch Zool XVIII(2), 225-270.

Nathusius von Königsborn W (1893). Die entwicklung der schale und der schalenhaut des hühnereies im oviduct des huhnes. Z Wissensch Zool 55, 576-584.

Nehrke G, Poignet H, Wilhelms-Dick D, Brey T \& Abele D (2012). Coexistence of three calcium carbonate polymorphs in the shell of the Antarctic clam Laternula elliptic. Geochem Geophys Geosyst 13, Q05014.

Neues F, Hild S, Epple M, Marti O \& Ziegler A (2011). Amorphous and crystalline calcium carbonate distribution in the tergite cuticle of moulting Porcellio scaber (Isopoda, Crustacea). J Struct Biol 175, 10-20.

Perez-Huerta A \& Cusack M (2009). Optimising electron backscatter diffraction (EBSD) of carbonate biominerals - Resin type and carbon thickness. Microsc Microanal 15, 197-203.

Perez-Huerta A \& Dauphin Y (2016). Comparison of the structure, crystallography and composition of eggshells of the Guinea fowl and graylag goose. Zoology 119, 52-63.

Pickford M (2014). New ratite eggshells from the Miocene of Namibia. Commums Geol Surv Namibia 15, 70-90.

Pickford M \& Senut B (1999). Geology and palaeobiology of the Namib desert, southwestern Africa. Mem Geol Surv Namibia 18, 1-155.

Portugal SJ, Bowen J \& Riehk C (2018). A rare mineral, vaterite, acts as a shock absorber in the eggshell of a communally nesting bird. Ibis 160, 173-178.

Ramesh K, Melzner F, Griffith AW, Gobler CJ, Rouger C, Tasdemir D \& Nehrke G (2018). In vivo characterization of bivalve larval shells: A confocal Raman microscopy study. J R Soc Interface 15, 20170723. doi:10.1098/ rsif.2017.0723

Romanov AL \& Romanov AJ (1949). The Avian Egg. London: Chapman \& Hall, 918 p. 
Senut B (2000). Fossil ratite eggshells: A useful tool for Cainozoic biostratigraphy in Namibia. Communs Geol Surv Namibia 12, 421-428.

Solomon SE \& Baird T (1976). Studies on the egg shell (oviducal and oviposited) of Chelonia mydas L. J Exp Mar Biol Ecol 22, 145-160.

Thompson CM, North EW, White SN \& Gallager SM (2014). An analysis of bivalve larval shell pigments using micro-Raman spectroscopy. J Raman Spectrosc 45, 349-358.

Tullett SG, Board RG, Love G, Perrott HR \& Scott VD (1976). Vaterite deposition during eggshell formation in the cormorant, gannet and shag, and in 'shell-less' eggs of the domestic fowl. Acta Zool (Stockh) 57, 79-87.

Tyler C (1969a). Avian egg shells: Their structure and characteristics. Int Rev Gen Exp Zool 4, 81-130.
Tyler C (1969b). A study of the egg shells of the gaviiformes, procellariiformes, podicipitiformes and pelecaniformes. J Zool 158, 395-412.

Urmos J, Sharma SK \& Mackenzie FT (1991). Characterization of some biogenic carbonates with Raman spectroscopy. Am Mineral 76, 641-646.

Uygur S, Ozmen S, Kandal S, Lortlar N, Omeroglu S, Arac M \& Cenetoglu S (2011). Reconstruction of cranial bone defects using Struthio camelus eggshell. J Craniofac Surg 22(5), 1843-1846.

Ylmen R \& Jäglid U (2013). Carbonation of Portland cement studied by diffuse reflection Fourier transform infrared spectroscopy. Int J Concrete Struct Mater 7, 119-125.

Zhang G, Xie X \& Wang Y (2001). Raman spectra of nacre from shells of main pearl-culturing mollusk in China. Spectrosc Spect Anal 21(2), 193-196. 